Pensamiento Crítico Vol.17. №2, pp. 27-34

\title{
Tasa de interés de créditos otorgados por la banca múltiple en el Perú
}

Mg. Gaby Cortez Cortez

\section{RESUMEN}

La estructura de las tasas de interés activas que se cobran en el sistema bancario del Perú muestra una relación inversa respecto a la escala económica de las empresas que reciben los créditos de los bancos; es decir, se establecen tasas de interés activas preferenciales menores para clientes con mayor escala económica en el mercado de bienes y servicios, y tasas de interés activas más altas para clientes con una menor escala de negocio.

Palabras clave: tasas de interés activas, crédito bancario, empresas.

\begin{abstract}
The structure of lending rates charged in Peru's banking system shows an inverse relation to the economic scale of the companies that receive the loans from banks, ie establishing preferential lending rates to customers under more economic scale in the market for goods and services, and lending rates higher for customers with smaller scale of business.
\end{abstract}

Key words: lending rates, bank credit, firms. 


\section{Introducción}

La tasa de interés activa juega un doble papel en la estrategia de los bancos para el otorgamiento de créditos. Por un lado, establece tasas activas bajas para sus clientes preferenciales o empresas vinculadas, y por otro lado, cobra tasas más altas para otro grupo de clientes que reportan una masa de intereses importante para mantener un margen y tasas de rentabilidad esperadas por los bancos.

Las tasas de interés cobradas por los bancos guardan una relación con la escala de las empresas (clientes) que producen principalmente bienes y servicios para el mercado interno; es decir, los bancos denominados grandes mantienen lazos crediticios con empresas corporativas y grandes del mercado interno; los bancos medianos y pequeños se relacionan con empresas equivalentes hasta un nivel donde los bancos más pequeños están relegados a nichos pocos significativos, o a mercados en etapas iniciales de desarrollo, hasta que alcanzan cierto atractivo económico y son abordados por los bancos más grandes. El caso más conocido es el de los créditos otorgados a la pequeña y micro empresa, y consumo.

\section{Tasas de interés activas del sistema}

Las tasas de interés activas, sean en moneda nacional o en moneda extranjera (dólar americano), tienen una característica que se puede apreciar según el tipo de cliente. Esta tasa de interés se incrementa conforme la escala empresarial desciende. Los créditos a las microempresas reciben la tasa de interés más alta del sistema; siguen los créditos a las pequeñas empresas con tasas de interés activas unos puntos menores, y así sucesivamente hasta llegar a la escala empresarial más alta como los créditos corporativos que a su vez reciben la menor tasa de interés activa en ambas monedas (ver Cuadro N. ${ }^{\circ}$ ). A estos créditos se suman los créditos de consumo e hipotecarios. 


\section{Gaby Cortez Cortez}

Cuadro $\mathbf{N}^{\mathbf{0}}$ 1. Tasas de interés activas anuales en moneda nacional y extranjera por tipo de empresa (en porcentajes al 28/09/2012)

\begin{tabular}{|c|c|c|c|c|c|c|c|c|c|c|}
\hline \multicolumn{11}{|c|}{ Empresas } \\
\hline & \multicolumn{2}{|c|}{ Corporativo } & \multicolumn{2}{|c|}{ Grandes } & \multicolumn{2}{|c|}{ Medianas } & \multicolumn{2}{|c|}{ Pequeñas } & \multicolumn{2}{|c|}{ Micro } \\
\hline & $\mathrm{MN}$ & ME & $\mathrm{MN}$ & ME & $\mathrm{MN}$ & ME & MN & ME & MN & ME \\
\hline Continental & 5.14 & 4.83 & 7.57 & 7.76 & 12.50 & 12.11 & 21.43 & 21.73 & 33.11 & 26.63 \\
\hline Comercio & . & 8.53 & 12.87 & 11.08 & 13.68 & 14.78 & 26.64 & 15.57 & 32.49 & 20.47 \\
\hline Crédito & 5.96 & 3.12 & 7.38 & 5.26 & 10.18 & 8.11 & 19.13 & 11.12 & 28.22 & 13.24 \\
\hline Financiero & 7.50 & 6.56 & 10.73 & 7.48 & 11.95 & 10.17 & 24.94 & 9.01 & 38.14 & 13.00 \\
\hline Interamericano & 5.98 & 6.43 & 7.94 & 7.30 & 10.38 & 9.71 & 14.56 & 11.36 & 15.07 & 13.23 \\
\hline Scotiabank & 4.71 & 2.73 & 6.44 & 5.02 & 11.36 & 8.80 & 26.52 & 17.15 & 31.88 & 17.80 \\
\hline Citibank & 5.54 & 3.72 & 6.16 & 3.48 & 6.78 & 3.72 & - & . & - & - \\
\hline Interbank & 5.13 & 3.53 & 7.31 & 5.14 & 10.09 & 6.51 & 17.89 & 10.35 & 22.06 & 10.52 \\
\hline Mibanco & - & - & - & - & 19.12 & 15.79 & 25.02 & 17.56 & 36.25 & 19.54 \\
\hline HSBC & 8.00 & 6.31 & 9.34 & 7.89 & 12.25 & 10.79 & 12.80 & 11.59 & 11.65 & - \\
\hline Santander & 8.54 & 6.68 & 9.08 & 6.51 & 8.16 & 7.25 & - & - & - & - \\
\hline Promedio & 5.70 & 3.82 & 7.50 & 5.82 & 11.05 & 9.17 & 22.93 & 15.63 & 33.18 & 19.61 \\
\hline
\end{tabular}

- Para operaciones realizadas en los últimos 30 dias

\section{Tasa de interés de los créditos corporativos}

A setiembre de 2012 el promedio de tasas de interés activas en moneda nacional y extranjera, para créditos corporativos era de 5.70 por ciento y 3.82 por ciento, respectivamente.

Del conjunto de bancos que conforman el sistema los bancos Continental, Scotiabank, Citibank e Interbank tenían tasas activas en moneda nacional por debajo del promedio, con excepción del Banco de Crédito. Estos bancos a su vez concentran el 92.4 por ciento del total de créditos corporativos en moneda nacional. Del mismo modo, los bancos de Crédito, Scotiabank, Citibank e Interbank, exceptuando Continental tuvieron tasas activas en moneda extranjera por debajo del promedio, los que a su vez acumulan el 94.1 por ciento del total de créditos corporativos en moneda extranjera (ver el Cuadro N. ${ }^{\circ} 2$ ). 


\section{Pensamiento Crítico Vol. $17 \mathrm{~N}^{\circ} 2$}

Cuadro N. ${ }^{\circ}$ 2. Participación de los bancos en el crédito por tipo de empresa (en porcentajes a setiembre 2012)

\begin{tabular}{|l|cc|cc|cc|cc|cc|}
\hline \multirow{2}{*}{ Banco } & \multicolumn{2}{|c|}{ Corporativo } & \multicolumn{2}{|c|}{ Grandes } & \multicolumn{2}{c|}{ Medianas } & \multicolumn{2}{c|}{ Pequeñas } & \multicolumn{2}{c|}{ Micro } \\
\cline { 2 - 11 } & $\mathrm{MN}$ & $\mathrm{ME}$ & $\mathrm{MN}$ & $\mathrm{ME}$ & $\mathrm{MN}$ & $\mathrm{ME}$ & $\mathrm{MN}$ & $\mathrm{ME}$ & $\mathrm{MN}$ & $\mathrm{ME}$ \\
\hline Continental & 33.0 & 15.0 & 35.6 & 23.3 & 42.9 & 30.3 & 9.4 & 22.6 & 6.3 & 25.4 \\
Comercio & 0.01 & 0.03 & 0.4 & 0.3 & 0.4 & 0.5 & 0.5 & 0.2 & 0.8 & 0.4 \\
Crédito & 29.3 & 52.4 & 29.8 & 42.4 & 28.3 & 29.4 & 39.1 & 24.4 & 20.2 & 28.4 \\
Financiero & 0.1 & 1.3 & 1.9 & 2.5 & 2.9 & 3.1 & 4.7 & 0.9 & 8.1 & 2.0 \\
Interamericano & 3.0 & 1.7 & 4.3 & 3.4 & 4.6 & 5.6 & 0.7 & 3.7 & 0.5 & 4.5 \\
Scotiabank & 20.4 & 13.0 & 15.5 & 13.7 & 10.3 & 18.7 & 17.0 & 28.0 & 7.7 & 20.4 \\
Citibank & 1.5 & 2.8 & 5.0 & 1.5 & 1.2 & 0.3 & - & - & - & - \\
Interbank & 8.2 & 10.9 & 5.2 & 9.0 & 6.5 & 9.0 & 3.8 & 5.2 & 1.4 & 2.5 \\
Mibanco & 0.1 & - & 0.2 & 0.1 & 1.1 & 0.5 & 24.6 & 14.5 & 55.1 & 16.2 \\
HSBC & 1.2 & 0.7 & 1.1 & 2.0 & 0.9 & 1.8 & - & & 0.3 & 0.2 \\
Santander & 4.2 & 2.2 & 1.0 & 1.7 & 0.9 & 0.9 & 0.03 & 0.2 & - & - \\
\hline Total & 100 & 100.0 & 100.0 & 100.0 & 100.0 & 100.0 & 100.0 & 100.0 & 100.0 & 100.0 \\
\hline
\end{tabular}

Fuente: Superintendencia de Banca y Seguros. Elaboración propia.

Estos créditos corporativos constituyen el 12.53 por ciento del total de créditos directos otorgados por la banca en moneda nacional, y el 25.45 por ciento en moneda extranjera (ver el Cuadro 3). Como se puede observar existe un mayor porcentaje a favor del total créditos otorgados por la banca en moneda extranjera a las empresas corporativas con tasas bastante preferenciales. Cabe señalar que es el Banco de Crédito el que ofrece la menor tasa activa de 3.12 por ciento con una participación del 52.4 por ciento del total de créditos otorgados a este sector, siendo su más cercano seguidor el Banco Continental con una participación del 15 por ciento, y con una tasa activa algo más elevada de 4.83 por ciento.

\section{Tasas de interés de los créditos a grandes empresas}

Los créditos para las grandes empresas tienen tasas activas en promedio más elevadas que las correspondientes a los créditos corporativos: 7.50 por ciento para créditos en moneda nacional, y 5.82 por ciento para moneda extranjera. Al igual que para los créditos corporativos, los créditos para grandes empresas son atendidos por los bancos denominados grandes (Crédito, Continental, Scotiabank e Interbank) cubriendo el 86.1 por ciento del total de créditos destinados a grandes empresas en moneda nacional, y 88.4 por ciento en moneda extranjera del total de créditos destinados a grandes empresas. 


\section{Gaby Cortez Cortez}

Cuadro N. ${ }^{\circ}$ 3. Participación de los Bancos en el crédito por empresas (en porcentajes al 29/09/12)

\begin{tabular}{|lccc|}
\hline Empresas o sector & $\mathrm{MN}$ & $\mathrm{ME}$ & Total \\
\hline Corporaciones & 12.53 & 25.45 & 19.03 \\
Grandes & 8.90 & 25.23 & 17.12 \\
Medianas & 12.21 & 25.4 & 18.85 \\
Pequeñas & 13.88 & 4.09 & 8.95 \\
Microempresas & 3.02 & 0.59 & 1.79 \\
Consumo & 32.52 & 3.96 & 18.18 \\
Hipotecario & 16.89 & 15.28 & 16.08 \\
\hline Total & 100.00 & 100.00 & 100.00 \\
\hline
\end{tabular}

Fuente: Superintendencia de Banca y Seguros. Elaboración propia.

Aquí también se puede observar una inclinación de los créditos destinados en las diferentes monedas, con un 8.9 por ciento del total de créditos destinados en moneda nacional frente a un 25.23 por ciento de créditos en moneda extranjera, tal como puede verse en el Cuadro 3. Nuevamente, el Banco de Crédito es el que cubre el mayor porcentaje de créditos con un 42.4 por ciento en moneda extranjera, seguido por el Banco Continental con un 23.3 por ciento como se observa en el Cuadro 2. En cuanto a las tasas de interés activas, el Banco de Crédito cobra 7.38 por ciento en moneda nacional, y el Banco Continental 7.57 por ciento. En moneda extranjera el Banco de Crédito cobra 5.26 por ciento, y el Banco Continental 7.76 por ciento. El Citibank cobra tasas activas por debajo del Banco de Crédito pero con una participación muy pequeña en este segmento con 5.0 por ciento en moneda nacional del total de créditos otorgados a las grandes empresas, y 1.5 por ciento en moneda extranjera, lo que nos lleva a pensar que la participación del Citibank, si bien no es muy importante, se mantiene de manera competitiva, tal como se observa en el Cuadro N. ${ }^{\circ} 2$.

\section{Tasas de interés de los créditos a medianas empresas}

Nuevamente se puede notar que este segmento tiene tasas en promedio más altas que las que se cobran para los créditos corporativos y créditos a grandes empresas: 11.05 por ciento en moneda nacional, y 9.17 por ciento para moneda extranjera (ver 


\section{Pensamiento Crítico Vol. $17 \mathrm{~N}^{\circ} 2$}

el Cuadro 1). En estas empresas se concentra la participación de un número mayor de bancos, lo que demuestra el deseo de los bancos de competir para captar un mayor número de clientes. Las empresas medianas concentran el 12.21 por ciento del total de créditos otorgados en moneda nacional, y el 25.23 por ciento en moneda extranjera (ver el Cuadro 3). En este segmento, el Banco Continental es el que lidera los créditos en ambas monedas con 42.9 por ciento de participación en moneda nacional, y con un 30.3 por ciento en moneda extranjera (ver Cuadro 2). Si bien la participación del Banco de Crédito queda relegada a un segundo lugar en este segmento, el cual para no perder competitividad cobra tasas algo menores que del Banco Continental. El Banco de Crédito cobra en moneda nacional 10.18 por ciento, versus 12.50 por ciento del Banco Continental. En cuanto a las tasas en moneda extranjera el Banco de Crédito cobra 8.11 por ciento, versus 12.11 por ciento que cobra el Continental. Cabe señalar

que el Banco Citibank cobra las menores tasas (6.78 por ciento en moneda nacional, y 3.72 por ciento en moneda extranjera) pero con una participación no muy importante: 1.2 por ciento del total de créditos en moneda nacional, y 0.3 por ciento en moneda extranjera.

\section{Tasas de interés de los créditos a la pequeña empresa}

Este segmento guarda la misma característica en cuanto al comportamiento de las tasas de interés; es decir, son más elevadas que en los anteriores grupos de empresas. La tasa activa promedio en moneda nacional es de 22.93 por ciento, y la tasa en moneda extranjera es de 15.63 por ciento. Este es un sector que se ha venido desarrollando en los últimos tiempos con el ingreso de los bancos denominados grandes, representando el 13.88 por ciento del total de créditos otorgados por el sistema bancario en moneda nacional, y el 4.09 por ciento en moneda extranjera. Cabe señalar que la participación de Mibanco, ha pasado de ser un banco denominado pequeño a un banco con características de mediano, aunque todavía poco competitivo si lo comparamos con los bancos denominados grandes que han ingresado a este sector de empresas. Tres son los bancos que tienen una mayor participación en el crédito a la pequeña empresa: el Banco de Crédito (39.1 por ciento en moneda nacional y 24.4 por ciento en moneda extranjera), Scotiabank (17.0 por ciento en moneda nacional y 28.0 por ciento en moneda extranjera) y Mibanco (24.6.por ciento en moneda nacional y 14.5 por ciento en moneda extranjera). Respecto a las tasas de interés, los bancos Interamericano de Finanzas e Interbank cobran las tasas más competitivas: 14.56 por ciento en moneda 


\section{Gaby Cortez Cortez}

nacional y 11.36 por ciento en moneda extranjera, y 17.89 por ciento en moneda nacional y 10.35 en moneda extranjera, respectivamente; pero con una escasa participación en el total de créditos (ver Cuadro 2). Dentro de los bancos con mayor participación en los créditos otorgados a las pequeñas empresas, el Banco de Crédito cobra las tasas más competitivas (19.13 por ciento en moneda nacional y 11.12 por ciento en moneda extranjera), algo cerca el Scotiabank (26.52 por ciento en moneda nacional y 17.15 por ciento en moneda extranjera), y Mibanco (25.02 por ciento en moneda nacional y 17.56 por ciento en moneda extranjera).

\section{Tasa de interés a la microempresa}

Este es un segmento empresarial todavía en formación, en el que se cobran las tasas activas más altas del sistema y por otro lado con un amplio dominio de dos bancos: Mibanco con una participación del 55.1 por ciento de los créditos en moneda nacional y 16.2 por ciento en moneda extranjera, y el Banco de Crédito con una participación del 20.2 por ciento en moneda nacional y 28.4 por ciento en moneda extranjera. Sin embargo, este sector empresarial tiene una atención reducida en el total de créditos ascendente a 3.02 por ciento en moneda nacional y de 0.59 por ciento en moneda extranjera. En cuanto a las tasas de interés las tasas más altas las cobra Mibanco con 36.25 por ciento en moneda nacional y 19.54 por ciento en moneda extranjera, siendo el promedio de mercado de 33.18 por ciento en moneda nacional y 19.61 en moneda extranjera. El Banco de crédito cobra 28.22 por ciento en moneda nacional y 13.24 por ciento en moneda extranjera demostrando una mayor competitividad.

\section{Conclusiones}

Las tasas de interés activas que cobran los bancos del sistema bancario del Perú, sean en moneda nacional o en moneda extranjera (dólar americano), muestran un nivel diferenciado por tipo de cliente, donde las tasas se elevan conforme la escala económica de las empresas se reduce y viceversa.

Tomando el sistema en conjunto las tasas de interés activas promedio a setiembre de 2012 confirman la estructura diferenciada por tipo de cliente. Las empresas corporativas reciben tasas menores del orden de 5.70 por ciento para créditos en moneda nacional, y 3.82 por ciento en moneda extranjera. Al otro extremo las microempresas pagan por sus 


\section{Pensamiento Crítico Vol. $17 \mathrm{~N}^{\circ} 2$}

créditos tasas de 33.18 por ciento en moneda nacional y 19.61 por ciento en moneda extranjera.

La escala de los bancos denominados grandes (principalmente el Continental y Crédito, seguido por los bancos Scotiabank e Interbank) determinan el promedio de las tasas de interés que rigen como referencia para cada tipo de crédito y el nivel de competitividad del mercado bancario en el Perú.

\section{Referencias bibliográficas}

Boletines y Memorias de la Superintendencia de Banca y Seguros 